\title{
Final height of patients who underwent bone marrow transplantation during childhood
}

Amnon Cohen, Attilio Rovelli, Maria Teresa Van-Lint, Cornelio Uderzo, Angelo Morchio, Chiara Pezzini, Giuseppe Masera, Andrea Bacigalupo, Cesare Romano

\begin{abstract}
Objective-To determine the impact on final adult height of bone marrow transplantation.

Methods-The final height of 28 long term survivors (18 males; 10 females), allografted before or at the onset of puberty, at a median age of 10.8 years (range 6.3 to 14.6) and who did not receive growth hormone (GH) treatment or other growth promoting agents, was evaluated. Median follow up period after bone marrow transplantation was 7.9 years (range 3.2 to 11.4), and age at the most recent evaluation 18.1 years (range $15 \cdot 6$ to $24 \cdot 5$ ). Height values were expressed in standard deviation score (SDS) from the mean of the normal population. Height at bone marrow transplantation was compared with final height as well as with parental genetic height. Patients were divided into three groups: severe aplastic anaemia (SAA): three patients given no radiotherapy; leukaemia-total body irradiation (TBI): 14 patients with acute or chronic leukaemia conditioned with chemotherapy and TBI; leukaemia-TBI with previous cranial radiation therapy (CRT): 11 patients. None of the patients had solid tumour.
\end{abstract}

Results-There was a decrease in final height SDS compared to pre-transplantation height SDS (paired $t$ test, $\mathbf{p}<0.0001$ ). All patients except one reached an adult height above $-2 \cdot 0$ SDS. A significant decrease in height SDS was found in the TBI and the CRT groups (paired $t$ test, $\mathbf{p}=0.02$ and $\mathbf{p}=0.0002$, respectively). Whereas height SDS value at the time of transplant was higher than the genetic height SDS, final height SDS values were lower.

Conclusions-Despite the decrease in height SDS found after bone marrow transplantation, 27 of the 28 patients spontaneously achieved what is considered to be a normal height SDS (above $-2 \cdot 0$ SDS). This should be taken into account when considering GH treatment in children who underwent bone marrow transplantation for malignant haematological diseases. (Arch Dis Child 1996; 74: 437-440)

Keywords: bone marrow transplantation, growth, final height, late effect.

Impaired growth has been observed in children after bone marrow transplantation, and is probably associated with the radiotherapy and chemotherapy given. ${ }^{1}$ Several studies have considered growth and growth rate in children after bone marrow transplantation ${ }^{2-6}$ but the follow up was short and the final height of these patients is not known. In a period of expanding use of recombinant human growth hormone $(\mathrm{hGH})$ treatment in this group of patients, ${ }^{78}$ it is important to determine the spontaneous growth and final adult height of these children.

In this study we evaluated the final height achieved by patients who had bone marrow transplantation for haematological diseases during childhood and had never been treated with growth hormone preparations.

\section{Methods}

Of a cohort of 207 children transplanted in the San Martino $(n=112)$ and San Gerardo Hospital ( $n=95)$ since 1976, 28 long term survivors (18 males; 10 females) who received an allogeneic bone marrow transplantation before 15 years of age from an HLA matched sibling have reached their final height. Our criterion for final height was either at least six months without height gain or a documented complete closure of the hand, wrist, and iliac crest epiphyses. None of the patients received growth hormone treatment or other growth promoting agents.

The mean age of the 28 patients at bone marrow transplantation was 10.8 (SD 2.2) years (range $6 \cdot 3$ to 14.6 ); the mean age at the most recent follow up examination was 18.7 $(2 \cdot 1)$ years (range $15 \cdot 6$ to $24 \cdot 5$ ), with a mean follow up period after transplantation of 7.9 $(2 \cdot 1)$ years (range $3 \cdot 2$ to $11 \cdot 4)$. Twenty three of the patients had no signs of puberty at the time of transplantation. The remaining five were at puberty stage 2 (breast buds in the girls and testicular volume between 4 and $6 \mathrm{ml}$ ).

Patients were divided into three groups according to their primary disorder and according to the conditioning regimen used:

Severe aplastic anaemia group (SAA) - Three patients $(2 \mathrm{M} ; 1 \mathrm{~F})$ with SAA aged $7 \cdot 4,9 \cdot 2$, and 12 years; conditioning included cyclophosphamide only, at a dose of $100 \mathrm{mg} / \mathrm{kg}$ a day for two consecutive days.

Leukaemia-total body irradiation group (TBI) 14 patients $(7 M ; 7 \mathrm{~F})$, median age 11.9 years (range 8.8 to 14.6 ) with acute or chronic leukaemia (two acute lymphoblastic leukaemia, ALL; nine acute non-lymphoblastic leukaemia, ANLL; two chronic myeloid leukaemia, CML); the conditioning regimen included cyclophosphamide $60 \mathrm{mg} / \mathrm{kg} / \mathrm{d}$ for two consecutive days 
Figure 1 Final adult height SDS distribution in patients who underwent BMT during childhood compared with height SDS at the time of

transplantation and also with corrected mid-parental height (cMPH). Numerals indicate the number of patients studied in each group. The dotted area indicates the height SDS distribution for the normal population. The short lines indicate the median height value for each column.

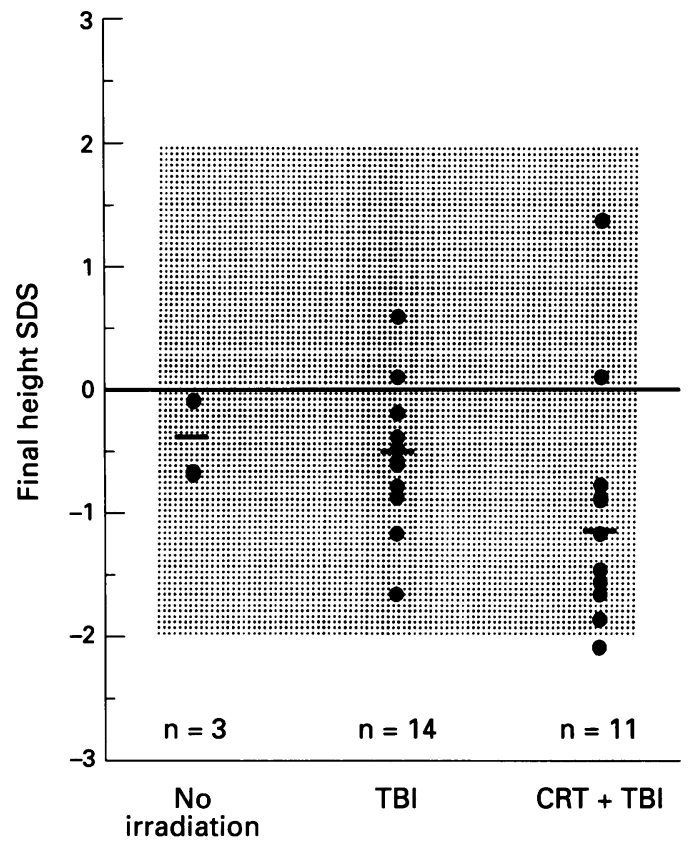

and TBI. Three had a $10 \mathrm{~Gy}$ single dose TBI, six had a total dose of 8.6-10 Gy TBI divided in three doses, and the remaining five had $12 \mathrm{~Gy}$ TBI given in six doses ( 3 Gy twice a day for three consecutive days).

ALL-TBI with previous cranial radiation therapy group $(C R T)-11$ patients $(9 \mathrm{M} ; 2 \mathrm{~F})$, median age 9.9 years (range 6.3 to 12.8 ) with ALL who had cranial radiation therapy as part of their first line treatment protocol. Five children received 18 Gy CRT and the remaining six patients received $24 \mathrm{~Gy}$. These children also received cyclophosphamide and TBI (single dose in one patient, three and six divided doses in two and eight patients, respectively) before bone marrow transplantation.

Graft-versus-host disease (GVHD) prophylaxis consisted either of cyclosporin A alone or in combination with methotrexate. Acute GVHD was observed in 17 patients (grade I-II in 14; grade III-IV in only three). Twelve developed chronic GVHD, limited (grade I according to the Seattle criteria) ${ }^{9}$ in seven cases and extended (grade II-III) in five. Treatment for chronic GVHD consisted of cyclosporin A, steroids azathioprine, or combination treatment.

The height of each patient was measured at bone marrow transplantation and during the most recent follow up examination with a wall mounted Harpenden stadiometer, and was expressed as standard deviation score (SDS) from the mean of the normal population. ${ }^{10}$ The genetic height (corrected mid-parental height: $\mathrm{cMPH}$ ) was established by measuring the heights of both parents and expressing their mean height as SDS [CMPH $=$ (mother's SDS + father's SDS)/2].

In order to determine the significance of the change in height SDS observed in the individual patients between the two time points, each patient's height SDS measured at the time of bone marrow transplant was compared with his own height SDS at the most recent follow up examination and also with his CMPH-SDS (his genetic height) using the Student $t$ test.
These differences in height SDS values within the subgroups TBI and CRT were examined using the Student $t$ test as well. The effect of sex, age at bone marrow transplant, and the severity of chronic GVHD on final height was also considered.

\section{Results}

Age at bone marrow transplantation was not significantly different in the three groups ( $t$ test). In 23 of the 28 patients a decrease in height SDS was observed from bone marrow transplantation to final adult height (2/3 in the SAA group; $10 / 14$ in the TBI group; all 11 patients in the CRT group).

Considering the whole cohort of 28 patients together (fig 1), height SDS at the time of bone marrow transplantation was significantly higher than the final height SDS: mean 0.31 (SD $1 \cdot 26$ ), range -2.66 to $+2.40 v$ mean $-0.78(0 \cdot 77)$, range $-2 \cdot 14$ to $1 \cdot 40$; mean difference 1.09 , SE $0.21, \mathrm{p}<0.0001$. The same comparison made within the different groups revealed that patients in the TBI group had a significant decrease in mean height SDS from $0.25(1.4)$ (range -2.66 to $+2 \cdot 29$ ) at the time of bone marrow transplantation to -0.66 $(0.59)$ (range -1.71 to +0.6$)$ of final height; mean difference 0.91 , SE $0.34, p=0.02$. The decrease in patients in the CRT group was even greater, from mean $0.44(1.26)$ (range -1.34 to +2.4 ) to mean $-1.02(1.01)$ (range $-2 \cdot 14$ to $+1 \cdot 4)$; mean difference $1 \cdot 46$, SE $0 \cdot 26, p=0.0002$. The change in height SDS observed in the SAA group was not evaluated statistically because of the small number of patients (fig 2). At the time of writing, the patient who was particularly short at the time of her bone marrow transplant $(-2.6 \mathrm{SDS})$ was a $27 \cdot 3$ year old woman (fig 1). At age 12 she was diagnosed as having AML and an allogeneic bone marrow transplant was performed 11 months later. Pre-transplant conditioning

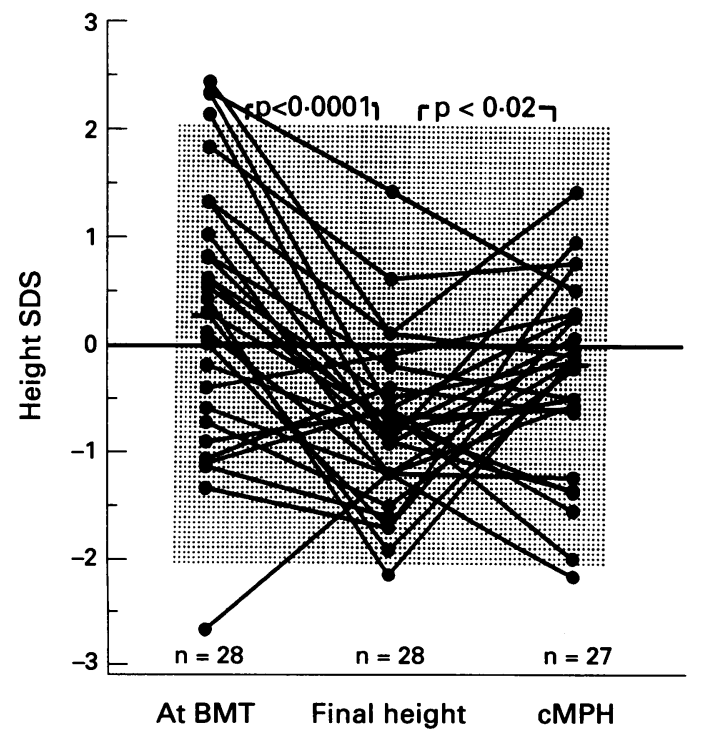

Figure 2 Adult final height SDS distribution in the three groups of patients studied. Numerals indicate the number of patients studied in each group. The dotted area indicates the height SDS distribution for the normal population. The short horizontal lines indicate the median height value for each column. 
treatment included cyclophosphamide 120 $\mathrm{mg} / \mathrm{kg}$ and fractionated TBI $(3.3 \mathrm{~Gy} \times 3)$. Height at the time of transplant was $141 \mathrm{~cm}$ $(-2.66$ SDS), weight $36.0 \mathrm{~kg}$. Anti-GVHD prophylaxis treatment after transplantation included cyclosporin A for one year and cortisone for two months. Puberty started spontaneously at age 15 (three years after the transplant), and menarche appeared at age 17 (her mother had menarche at age 16). The particularly short stature at the time of the transplant and the positive change in height SDS observed in this patient are therefore probably due to a constitutional delay of growth and puberty which would have been present whether or not she had received a bone marrow transplant.

Despite the general trend of decrease in height SDS found after bone marrow transplantation, only one patient presented what is considered to be a pathological SDS value, that is, below -2 . This subject was in the CRT group and was exposed to 18 Gy CRT and 3 Gy $\times 3$ fractions of TBI.

Height SDS value at the time of bone marrow transplantation was significantly higher than that of the genetic cMPH ( $t$ test; $\mathrm{p}=0.028$ ). On the other hand, the mean final height SDS was significantly lower than the genetic $c M P H$ values $(p=0 \cdot 014)$. Analysing the TBI and the CRT groups separately, final height SDS was significantly lower than $\mathrm{CMPH}$ SDS only in the CRT group $(\mathrm{p}=0.022)$.

A good correlation $(r=0.48, p=0.01)$ was found between the age at transplantation and the degree of loss in SDS when analysing the whole cohort of 28 patients (fig 3 ). This was primarily due to the loss in SDS observed in the CRT group $(r=0.68 ; \mathrm{p}<0.02)$.

The occurrence and grade of chronic GVHD did not influence the extent of height SDS changes. The mean value of the change in SDS (height SDS at bone marrow transplantation minus final height SDS) found in the 16 patients who did not develop chronic GVHD was $-0.89(1.2)$ compared to a mean value of

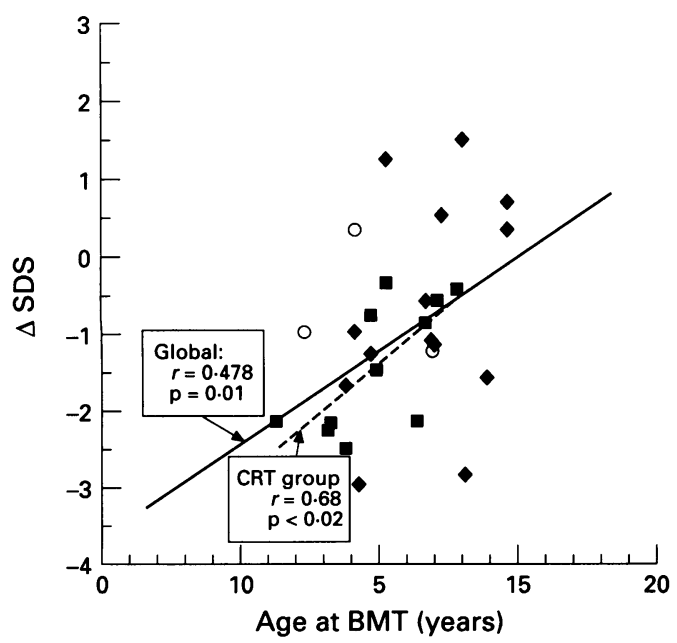

Figure 3 A correlation between the age at the time of transplantation and the delta-SDS (final height

$S D S-S D S$ at BMT). Continuous line: regression line of all 28 patients studied. Dashed line: regression line of the CRT group only. $S A A$ group= empty circle; $T B I$ group $=$ filled diamond; $C R T$ group $=$ filled square .
$-1.36(0.90)$ in the 12 patients who developed chronic GVHD (Student $t$ test, $\mathrm{p}=0 \cdot 16$ ). Gender did not influence the extent of height SDS changes. All 18 males started and completed pubertal maturation spontaneously, while in five out of the 10 females, replacement sex hormone treatment was begun at a median age of 16.1 (range 15-17.9 years) because of hypergonadotropic hypogonadism.

\section{Discussion}

Growth impairment is a common observation in children treated for leukaemia. ${ }^{11-14}$ Final height was reported to be significantly reduced in children with ALL who received only chemotherapy or chemotherapy in combination with different doses of CRT. ${ }^{15}$

The increasing number of long term survivors after bone marrow transplantation has focused attention on the additional effect of this procedure on growth. ${ }^{1-8}$ Most children who undergo allogeneic bone marrow transplantation have already been given combination chemotherapy as first or second line treatment for leukaemia, and some of them have also been exposed to cranial radiotherapy. The impaired growth seen in children who underwent bone marrow transplantation is usually observed in those who received irradiation therapy, and is probably due to a variety of factors such as lesions to the bone epiphyses and hormone deficiencies (growth hormone, sex hormones, thyroid hormones).

Most studies dealing with the growth of patients with haematological disorders who underwent bone marrow transplantation report only limited data for the first few years after transplantation. ${ }^{1-6}$ As bone marrow transplantation in childhood has been employed only during the last two decades, data on final adult height achieved by these patients are scanty. ${ }^{816}$ Furthermore, some children with a reduced growth rate after transplantation are treated with hGH in the absence of full knowledge of what the spontaneous final height would have been. ${ }^{17-19}$

In this study we analyse the final height achieved by a relatively homogeneous group of patients with haematological diseases only (patients with solid tumours were excluded from the study group), who underwent allogeneic bone marrow transplantation during childhood. The final height of these patients was found to be lower than the predicted final height, based on both height SDS at the time of transplantation and genetic parental height (fig 1). The greatest loss in height was observed in the irradiated groups, and in particular in patients who received prior CRT. The decrease in height SDS (mean $1 \cdot 09$, SD $1 \cdot 10$ ) suggests that the change in height SDS is likely to lie between $+1 \cdot 1$ and $-3 \cdot 3$ SDS.

Interestingly, despite the altered growth and reduced final height, 27 of the 28 patients studied have reached height SDS values comparable to those of the normal population (that is, from $-2 \cdot 0$ to $+2 \cdot 0$ ). A similar final height distribution was reported by Dacou-Voutetakis 
et al in 20 children with ALL who did not undergo bone marrow transplantation. ${ }^{13}$

In the long term, chronic GVHD seems not to have any deleterious effect on the final height of these patients $(p=0 \cdot 16)$. This is in disagreement with some reports in which chronic GVHD was found to be one of the factors causing short term growth impairment. ${ }^{13}$ This suggests that the period of chronic GVHD (the disease itself and its treatment) might be associated with growth impairment, and that a catch up in growth will follow after healing.

Davis $e t$ al have recently suggested that the impaired growth observed in surviving children with ALL is likely due to a disturbance of pubertal growth in combination with a direct toxic effect of chemotherapy on the cartilage growth plate, leading to skeletal disproportion. ${ }^{14}$ On the other hand, it appears from our data that the younger these children are at the time of transplantation, the more profound will be the loss in height SDS (fig 3). This means that the loss in height is a constant and continuous process, even during prepuberty.

The effect of the timing of puberty (spontaneous or induced by replacement sex hormone therapy) does not seem to play a role in the change in height SDS observed in our cohort of patients. In fact Dickerman et al ${ }^{20}$ showed that the timing of the start of treatment with sex hormone in patients with isolated gonadotropin deficiency does not influence final height values.

In conclusion, growth impairment in children given bone marrow transplants for haematological diseases is due to a variety of factors such as chemotherapy/radiotherapy and immunosuppressive treatment, and therefore to damage to the cartilage growth plate and, to some extent, hormone insufficiency. Since in our study most patients who underwent bone marrow transplantation during childhood spontaneously reached final heights that were lower than expected but within the normal range for the healthy population, and since a possible interaction of $\mathrm{GH}$ with residual leukaemic cells cannot be excluded, ${ }^{21}$ concern should be raised about the use of hGH in this group of children. We therefore recommend that only children with severe height loss after bone marrow transplantation, identified by frequent clinical evaluations, should be considered for laborious pituitary-hypothalamic function tests. The decision to start hGH treatment should be made very carefully. For the moment, none of our transplanted children has needed hGH treatment.

This work was supported by Comitato Verga per lo studio e la cura della leucemia del bambino, Associazione Ricerca Trapianto del Midollo Osseo (ARITMO), Associazione Italiana Ricerca Cancro (AIRC), Associazione Italiana Leucemia (AII), and Associazione Crescere Insieme.

1 Sanders JE, Pritchard S, Mahoney P, et al. Growth and development for bone marrow transplantation for leukemia. Blood 1986; 68: 1129-35.

2 Hovi L, Rajantie J, Perkkio M, et al. Growth failure and growth hormone deficiency in children after bone marrow growth hormone deficiency in children after bone marrow 1990; 5: 183-6.

3 Shinohara O, Kato S, Yabe H, et al. Growth after bone marrow transplantation in children. Am $\mathcal{f}$ Pediatr Hematol Oncol 1991; 13: 263-8.

4 Willi SM, Cooke K, Goldwein J, et al. Growth in children after bone marrow transplantation for advanced neuroblastoma compared with growth after bone marrow transplantation for leukemia or aplastic leukemia. $f$ Pediat 1992; 120: 726-32.

5 Wingard JR, Plotnick LP, Freemer CS, et al. Growth in children after bone marrow transplantation: Busulfan plus children after bone marrow transplantation: Busulfan plus body irradiation. Blood 1992; 79: 1068-73.

6 Cohen A, Van-Lint MT, Uderzo C, et al. Growth in patients after allogeneic bone marrow transplant for hematological diseases in childhood. Bone Marrow Transplant 1995; 15: 343-8.

7 Olshan JS, Willi SM, Gruccio D, Moshang T. Growth hormone function and treatment following bone marrow transplant for neuroblastoma. Bone Marrow Transplant 1993; 12: 381-5.

8 Sanders J, Flowers M, Siadek M, McGuire T. Negative impact of prior central nervous system (CNS) irradiation on growth and neuropsychological function (NPF) after total body irradiation (TBI) and bone marrow transplant total body irradiation (TBI) and bone marrow tran
(BMT) [abstr]. Blood 1994; 81 (suppl 1): 986a.

9 Shulman HM, Sullivan KM, Waiden PL, et al. Chronic graftversus-host syndrome in man. Am $\mathcal{F}$ Med 1980; 69: 204-8.

10 Tanner JM, Goldstein H, Whitehouse RH. Standards for children's height at ages 2-9 years allowing for height of parents. Arch Dis Child 1970; 45: 755-62.

11 Zurlo MG, Senesi E, Terracini B, et al. Height of children off therapy after acute lymphoblastic leukemia. Pediat Hematol Oncol 1988; 5: 187-95.

12 Yamada S, Ishii E, Okabe Y, et al. Growth retardation in childhood leukemia and lymphoma. Am $\mathfrak{f}$ Pediatr Hemato Oncol 1992; 14: 236-40.

13 Dacou-Voutetakis C, Kitra V, Grafakos S, Polychronopolou S, Drakopoulou M, Haidas S. Auxologic data and hormonal profile in long-term survivors of childhood acute lymphoid leukemia. Am $\mathcal{J}$ Pediatr Hematol Oncol 1993; 15: 277-83

14 Davies HA, Didcock E, Didi E, Ogilvy-Stuart A, Wales JKH, Shalet SM. Disproportionate short stature after cranial irradiation and combination chemiotherapy for leukaemia. Arch Dis Child 1994; 70: 472-5.

15 Sklar C, Mertens A, Walter A, et al. Final height after treatment for childhood lymphoblastic leukemia: comparison of no cranial irradiation with 1800 and 2400 centigrays of cranial irradiation. $₹$ Pediatr 1993; 123: 59-64

16 Cohen A, van-Lint MT, Uderzo C, et al. Final height of patients after allogeneic bone marrow transplantation during childhood. In: Abstract book of the 15th International Symposium on Growth and Growth Disorder. Florence, 1993: 75.

17 Blatt J. Growth hormone and leukemia. Pediatr Hematol Oncol 1993; 10: 3-5.

18 Fradkin JE, Mills JL, Schonberger LB, et al. Risk of leukemia after treatment with pituitary growth hormone. ҰAMA 1993; 270: 2829-32.

19 Bozzola M, Giorgiani G, Locatelli $F$, et al. Growth in children after bone marrow transplantation. Horm Res children after bone.

20 Dickerman Z, Cohen A, Laron Z. Growth in patients with isolated gonadotrophin deficiency. Arch Dis Child 1992; 67: $513-6$.

21 Estrov Z, Meir R, Barak Y, Zaisov R, Zadik Z. Human growth hormone and insulin-like growth factor-1 enhance the proliferation of human leukemic blasts. $\mathcal{F}$ Clin Oncol 1991; 9: 394-9. 